\title{
AVALIAÇÃO DO PERFIL DE EGRESSOS DO PROGRAMA DE PÓS-GRADUAÇÃO STRICTO SENSU EM EDUCAÇÃO DA UFU: IMPACTO NA FORMAÇÃO DOCENTE E DE PESQUISADOR (2004-2009)
}

\author{
Humberto Marcondes Estevam* \\ Selva Guimarães**
}

Recebido: 13 dez. $2010 \quad$ Aprovado: 01 ago. 2011

\footnotetext{
* Pós-Doutor em Educação. Professor no Instituto Federal de Educação, Ciência e Tecnologia do Triângulo Mineiro - IFTM, Uberaba, MG, Brasil. E-mail: humberto@iftm.edu.br

** Pós-Doutora em Educação. Professora da Universidade Federal de Uberlândia - UFU, Uberlândia, MG, Brasil. E-mail: selva@ufu.br
}

Resumo: Este estudo verificou a trajetória acadêmica dos egressos do curso de Mestrado do Programa PósGraduação em Educação Escolar da Faculdade de Educação - FACED/UFU de Uberlândia no período de 2004 a 2009. O universo foi constituído de trezentos e quarenta e nove (349) egressos titulados, conseguimos contatar e enviar email para duzentos e quarenta e dois (242) egressos. Foram incluídos para a amostra, trinta e nove (39) sujeitos egressos do mestrado em educação que equivale a $11 \%$ do total de egressos. Destes, trinta e um (79\%) do gênero feminino e apenas oito $(21 \%)$ do gênero masculino. A maioria deles freqüentou escolas públicas na sua graduação, sobretudo na UFU. As principais razões que levaram os sujeitos a ingressarem no Mestrado foram a busca da carreira docente e o anseio de realizar pesquisa. O curso e o corpo docente foram considerados "muito bom e ótimo". A maioria deles não se dedicou integralmente ao curso, $26 \%$ publicaram suas Dissertações e cerca de 38\% atuam como orientadores de trabalhos, sendo setenta (70) o número de alunos sob orientação e de cerca de duzentos e oitenta e cinco (285) os de já orientados. Observou-se que a maioria dos sujeitos atua em Instituições públicas. A maioria escolheria a mesma profissão, cursaria o Mestrado, optaria pela mesma área e escolheriam o mesmo orientador. O estudo aponta que o medo da exclusão e da marginalização obriga seu aperfeiçoamento acadêmico, onde a educação está caracterizada como algo a ser consumido e que a escola valoriza o saber onde o atributo é socialmente definido como o "valor da educação". O Mestrado em Educação da UFU é um ensino plural de qualidade para a formação de docentes e de pesquisadores.

Palavras-chave: Educação. Avaliação egressos. Formação docente. Perfil egressos. Formação pesquisador. Educação escolar.

\section{PROFILE ASSESSMENT PROGRAM GRADUATES POST-GRADUATE \\ STUDIES IN EDUCATION AT UFU: IMPACT ON TEACHING AND RESEARCH (2004-2009)}

Abstract: This study examined the academic career of the graduates of the Master Program Graduate School of Education Faculty of Education - FACED / UFU Uberlândia in the period 2004 to 2009. The universe consisted of three hundred and forty nine (349) graduates, we were able to contact and send email to two hundred and forty-two (242) graduates. The sample consisted of thirty-nine (39) subjects enrolled in the master's degree in education, equivalent to $11 \%$ of the graduates. Of these, thirty-one $(79 \%)$ were females and eight $(21 \%)$ were male. Most of them attended undergraduate public schools, especially at the UFU. The main reasons for individuals to join the Masters Program were the pursuit of teaching careers and the desire to undertake research. Both the program as well as the faculty were considered as very good and excellent. Most of them are not fully devoted to the program, $26 \%$ reported their dissertations and about $38 \%$ work as advisors, and seventy (70) students are being advised and about two hundred and eighty-five (285) have already 
been advised. It was observed that most subjects work in public institutions. Most would choose the same profession, take the same Masters program, would choose the same field and the same advisor. The study indicates that the fear of exclusion and marginalization requires the individual's academic improvement, for education is characterized as something to be consumed and that the school values knowledge as a socially defined "educational value." The Master of Education program at the UFU is a quality education program for the training of teachers and researchers.

Key words: Education. Alumni evaluation. Educational formation. Alumni profile. Teacher education. School education.

\section{INTRODUÇÃO}

O vínculo profissional, disposto como instrutor e orientador de Sistemas de Gestão aplicados a pequenas, médias e grandes empresas, e o cotidiano de uma conceituada empresa de informática na cidade de Uberaba - MG no final da década de 80 proporcionou-me o exercício da primeira experiência como professor. Esta rotina foi por sua vez, um enfrentamento didático e pedagógico marcado por tentativas, erros e acertos com os diferentes perfis de usuários de computador e das mais diversas áreas de empresas, bem como suas categorias econômicas e sociais. Esta experiência contribuiu para um "despertar docente". Nasceu então, uma nova expectativa, que motivado, financeiramente, por esta mesma empresa de informática foi possível concluir com êxito o curso superior de Tecnologia em Processamento de Dados. Após a Graduação fui convidado a participar como professor de informática em outras escolas privadas que aderindo às novas tecnologias efetuavam treinamentos para professores de ensino fundamental e alunos. Cabe aqui ressaltar que muitas escolas na região e ao seu tempo montavam laboratórios de informática como forma de atrativos e ao mesmo tempo como diferencial de mercado. Todavia, se preocupava com os meios didáticos e pedagógicos aplicados e seus conteúdos. Pais e professores acreditavam que o computador somente servia para jogos eletrônicos, fato este, bastante intrigante e que trouxe atrasos didáticos e informações errôneas da necessidade e importância da informática na vida escolar, considerando, que na ocasião o número de softwares educativos não era grande como hoje.

$\mathrm{Na}$ década seguinte fui contratado como professor e coordenador de um curso técnico em Processamento de Dados em uma escola pública estadual onde vivenciei não só a atividade didática, mas, também, dificuldades e restrições do serviço público, principalmente, no que tange à educação. Desde então, o pensar docente me encantou abrindo novos caminhos norteados pelo aperfeiçoamento acadêmico. Desde julho de 2000 tenho vivenciado a experiência como docente universitário em algumas Instituições públicas e particulares. Com esta prática docente e observando as necessidades de se ampliar e disseminar a 
informação por meio das multimídias disponíveis realizamos uma pesquisa de Mestrado na área da educação intitulada "A Internet como ferramenta de apoio ao Ensino na Área da Saúde". Todo este direcionamento da busca pelo saber permitiu a continuidade de investigação e a partir de 2003 no Doutorado, nos propusemos pesquisar sobre a "Avaliação do perfil de egressos do programa de Pós-Graduação stricto sensu em educação escolar: impacto na formação docente e de pesquisador" na Universidade Estadual Paulista "Júlio de Mesquita Filho" - Faculdade de Ciências e Letras - Campus de Araraquara/SP.

No Pós-Doutorado na Universidade Federal de Uberlândia - UFU - Campus Santa Mônica, a proposta não foi diferente e continuamos no caminho intrigante que é a problemática da Avaliação. A falta de trabalhos similares acomete mais uma vez a nossa busca e contribuição para a educação e os sistemas de avaliação.

Durante muito tempo não era exigido à divulgação on-line e a Secretaria da Pós-Graduação não tinha normas definidas por se tratar de uma tecnologia ainda em desenvolvimento como os sites e os sistemas de gestão acadêmica.

Este relatório apresenta resultados de uma investigação proposta para avaliar o perfil dos egressos do Programa de Pós-Graduação stricto sensu nível Mestrado em Educação da Universidade Federal de Uberlândia, considerando-se os impactos na formação docente e de pesquisador. Para esta investigação foi acordado o período de 2004 quando se forma a primeira turma do mestrado em educação até 2009, sendo o ano limite para o corte acordado conforme proposta inicial encaminhada à coordenação da pós-graduação para aprovação do plano de trabalho. Não foi indicado nesta pesquisa dados relativos ao doutorado por se tratar de um curso novo.

Este relatório abre perspectivas para que se efetivem novas avaliações de ingressos e egressos nos vários cursos de Pós-Graduação não só na universidade nele envolvida, mas também em outras, objetivando rever os projetos de incentivo e fomento à pesquisa; que estimule por parte do setor da Pós-Graduação da IES controles mais eficientes e atualizados dos dados relativos não só aos discentes e docentes, mas também da atualização contínua dos dados cadastrais e da situação acadêmica dos egressos, bem como estimular a sua interação com a Instituição; que seja feita uma avaliação sistematizada e contínua envolvendo ingressos e egressos dos diversos cursos; que se proceda à avaliação periódica dos cursos de Pós-Graduação, principalmente quando os mesmos passam por processos de transformação em seus modelos, como é o caso em particular da Instituição investigada.

Contudo, faz-se necessário alguns questionamentos aos egressos de cursos de Pós-Graduação como, por exemplo, qual a sua procedência, como foi sua 
trajetória acadêmica desde o ensino fundamental até a Graduação, qual e como foi seu caminhar na Pós-Graduação, quais as repercussões do processo na sua vida pessoal, acadêmica e profissional. Enfim, questionamentos que possam contribuir para mapear a situação atual da Pós-Graduação no tocante, não só ao curso propriamente dito, mas, principalmente, em relação ao pós-graduando e pós-graduado como indivíduo, sujeito de um processo mais amplo e intricado, qual seja a relação Instituição, educação e sociedade.

Considerando estas questões propusemos nesta pesquisa avaliar o perfil dos egressos do Curso de Mestrado do Programa de Pós-Graduação stricto sensu em Educação na UFU, considerando-se o impacto na formação docente e de pesquisador, identificando os perfis acadêmico e profissional e a situação atual dos egressos, investigando entre os mesmos os motivos que os levaram a cursar a Pós-Graduação, avaliando a contribuição da Pós-Graduação entre os egressos quanto à docência, pesquisa e a produção científica e, conhecendo seu grau de satisfação quanto a alguns aspectos da orientação, do curso e do corpo docente.

A hipótese que motivou estes questionamentos assenta-se no fato de que o ensino de Pós-Graduação em uma universidade, reconhecidamente, de altíssima qualidade, conceito 5 na Avaliação Capes, poderia contribuir para a formação de uma elite de pesquisadores em educação, o que resultaria na inserção destes sujeitos no âmbito educacional atuando no sentido da melhoria qualidade de ensino da educação básica e superior.

Este referencial da educação básica e superior pressupõe que os sujeitos pudessem estar engajados em programas e projetos pedagógicos que pudessem absorver estes profissionais titulados. Portanto, o que se pressupôs, inicialmente, foi que a perspectiva de titulação em nível de Mestrado em Educação permitisse a inserção destes sujeitos em ações pedagógicas e educativas que tivessem como parâmetro a melhoria da qualidade de ensino.

\section{AVALIAÇÃO E QUALIDADE DA EDUCAÇÃO}

Ao se apontar os diversos elementos que compõem a avaliação, ressaltam-se os imprescindíveis papeis nas mudanças organizacionais sendo considerados seus princípios voltados para a educação. Evidencia-se um conjunto de contribuições de autores que registram tanto a relevância do tema quanto a aplicação da abordagem cultural nas instituições de ensino.

A avaliação acontece na razão direta das relações e a busca pela qualidade domina os interesses de todos vinculados, organicamente, ao processo institucional. Os caminhos da busca pela qualidade e o conhecimento dos resultados são 
indispensáveis para o aprimoramento do processo de educar, motivo desafiador que se projeta na continuidade das ações educativas sempre em transformação. A avaliação, de modo consequente, é levada a cumprir papel central na funcionalização econômica da Educação Superior, nos conceitos e metodologias mais apropriados ao mercado, especialmente nas funções operacionais e pragmáticas de capacitação técnica para os empregos que aos propósitos amplamente educativos de formação humana integral (DIAS SOBRINHO, 2010). Este tema despertou o interesse de educadores e pesquisadores a partir dos anos 40 do século XX com os estudos de Ralph Tyler em 1942 sobre accountability, que no Brasil encontrou como tradução "prestação de contas" e que, de alguma forma exerceu forte influência na formulação de metodologias e realização de numerosos estudos e pesquisas. Com efeito, o final da década de 60 do referido século foi rico na produção acadêmica de estudos sobre avaliação. Cronbach (1963), Scriven (1967), Stake (1967), Stufflebeam et al (1971) entre outros, criaram modelos teóricos fundamentados na mensuração de valores que se propõem a identificar o desempenho monetário, material ou acadêmico, qualitativo ou quantitativo e obtiveram considerável êxito em suas propostas, influenciando uma geração de avaliadores da educação.

São muitos os críticos do emprego de modelos de avaliação, particularmente, aqueles baseados em medidas de valores de variáveis que compõem um indicador sob a argumentação de se constituírem em abordagens quantitativas sem apreço qualitativo. Stake (1967) aborda a questão com profundidade delineando as percepções do fenômeno educacional com precisão, onde a avaliação quantitativa identifica algumas variáveis, realiza medidas, explica os fenômenos e faz análise estatística. Da mesma forma, a avaliação qualitativa identifica eventos de interesse e seleciona algumas variáveis, processos, padrões de avaliação, registra e interpreta observações. Segundo Stake (1967) a avaliação qualitativa se resume a um pequeno número de casos e um grande número de variáveis e a avaliação quantitativa a um grande número de casos e um pequeno número de variáveis. Os argumentos a favor e contra a singularidade e a subjetividade são, muitas vezes, vistos como uma diferença entre as abordagens quantitativa e qualitativa na pesquisa e a distinção é importante, ainda que esses temas deem margem polêmicas e falsas dicotomias.

Essa prática é largamente utilizada em alguns países para efeito de legitimação de saberes, validação de instituições e reconhecimento oficial para o exercício de atividades profissionais. A avaliação por meio de exames, testes, provas, instrumentos antes aplicados a alunos quase somente no cotidiano escolar, passou a ser utilizada como um panorama da gestão de conjunto da 
educação, na esperança de que essas ferramentas ofereçam elementos para decisões políticas e burocráticas e tragam informações úteis aos professores e estudantes (DIAS SOBRINHO, 2010).

Os pesquisadores quantitativos fazem discriminações qualitativas, assim como os pesquisadores qualitativos descrevem importantes quantidades em seus relatórios de educação. É, justamente, nessa linha de raciocínio que a pesquisa se estruturou, propondo a construção de um conjunto de variáveis que não se confunda com a simples mensuração e, mais precisamente, com uma abordagem em que a medida é o preâmbulo da avaliação e pesquisa. Conforme Vianna (2000) a avaliação é a aplicação dos métodos da pesquisa na solução de problemas específicos de uma área. Sem dúvida, existe um traço comum entre pesquisa e avaliação qual seja, a busca do conhecimento para a compreensão dos fenômenos educacionais e a solução dos seus problemas Stufflebeam (1971). A pesquisa é julgada em função da sua validade interna e a avaliação pela sua utilidade e credibilidade (GLASS; WORTHEN, 1971). Para Polit e Hungler (1995) a validade centra-se na adequação da amostragem da área a ser medida, enfatizando a representatividade das perguntas do instrumento utilizado para a coleta dos dados que segundo Laville (1999), para coletar informação a propósito de fenômenos humanos, o pesquisador pode, segundo a natureza do fenômeno e a de suas preocupações de pesquisa, ou consultar documentos sobre a questão, ou encontrar essa informação observando o próprio fenômeno, ou ainda interrogar pessoas que o conhecem.

Conforme Dias Sobrinho (2000), a natureza essencial da universidade é, ineludívelmente educativa, pois educativos são todos os processos sociais de formação humana e todas as etapas e variadas formas e conteúdos de aprendizagens, de aquisição e de construção de atitudes, conhecimentos e valores. A universidade faz e refaz, cotidianamente, a sua convivialidade num espaço compartido e disputado, em que os valores dominantes devem ser, permanentemente, postos à confirmação. Por isso, os processos educativos vigoram num ethos de crítica, de rupturas e de transformações, que é o ethos da universidade zelosa de sua autonomia e de seu papel político, cheio de zonas indeterminadas e de situações incertas, conflituosas e únicas, que não cabem nos cânones rígidos e estreitos da racionalidade técnica. $\mathrm{O}$ economicismo conduz ao utilitarismo e ao pragmatismo, inimigos da liberdade acadêmica e da autonomia da universidade. Os saberes e aqueles que a eles se dedicam desviam-se de suas funções públicas de emancipação e construção de uma sociedade, de um sistema de vida humana baseado nos valores universais e perpétuos, para uma relação individualista e "coisificada". O saber se transforma numa coisa de posse individual e privada, 
que se usa e se vende como insumo mercadológico (DIAS SOBRINHO, 2000).

A Universidade é uma Instituição da sociedade com atribuições precisas de fazer ciência e produzir conhecimentos teóricos e práticos. Em sentido amplo ela deve promover a formação humana e, inseparavelmente, promover a sociedade. As diversas formas de avaliação que promove, sejam fragmentadas ou integradas, específicas ou globais, são deliberadas e objetiváveis. Enquanto processos promovidos por decisão e escolha de agentes da universidade, têm caráter público e suas diversas etapas podem ser analisadas e criticadas. Portanto, a própria avaliação pode ser avaliada, e convêm que o seja rigorosamente. A avaliação institucional não se compõe de atos reconhecidos como sujeitos de um processo oficial. Portanto, não se faz com atos difusos e isolados, cuja responsabilidade seria imprecisa e diluída, cujos objetivos e critérios não tivessem sido discutidos, coletivamente, e de modo institucional e cujos usos pudessem ser não pertinentes e, até mesmo, contraditórios em relação com a natureza e os compromissos básicos da Instituição. Ao contrário, a avaliação institucional é um processo intencional, resultado de vontade e opção políticas, um conjunto coerente de conceitos e práticas deliberada e socialmente organizadas, estruturadas e implementadas.

Entretanto, em que pese à racionalidade desse processo, não se deve esquecer também as suas tramas nutridas de contradições e dissensos, como costuma ser todo processo social. É relacional e integrada à constituição desse processo. A Avaliação Institucional é um dos componentes do Sistema Nacional de Avaliação da Educação Superior (SINAES) e está relacionada (INEP, 2010):

- à melhoria da qualidade da educação superior;

- à orientação da expansão de sua oferta;

- ao aumento permanente da sua eficácia institucional e efetividade acadêmica e social;

- ao aprofundamento dos compromissos e responsabilidades sociais das instituições de educação superior, por meio da valorização de sua missão pública, da promoção dos valores democráticos, do respeito à diferença e à diversidade, da afirmação da autonomia e da identidade institucional.

Os processos avaliativos devem constituir um sistema que permita a integração das diversas dimensões da realidade avaliada, assegurando as coerências conceitual, epistemológica e prática, bem como o alcance dos objetivos dos diversos instrumentos e modalidades (INEP, 2010). 
Silva e Brandão (2003) apontam a avaliação como um processo de aprendizagem sistemático e intencional que um indivíduo, grupo ou organização se propõe a percorrer para aprofundar a sua compreensão sobre determinada intervenção social, por meio da elaboração e aplicação de critérios explícitos de investigação e análise, em um exercício compreensivo, prudente e confiável, com vistas a conhecer e julgar o mérito, a relevância e a qualidade de processos e resultados.

Para Dias Sobrinho (2000), avaliar é estabelecer os critérios de avaliação. Estes critérios são estabelecidos a partir de um corpo de informações coerentes e pertinentes, onde a interpretação e a atribuição de juízos de valor são essenciais para sustentação das articulações de transformação. Num processo de avaliação, os critérios estão intimamente relacionados com os objetivos estabelecidos, o que, aliás, lhes confere um sentido prático. Esses critérios são operacionais e explicativos na medida em que são produzidos pelos agentes coletivos e identificados socialmente como sendo os marcos e padrões a que devem referir-se os objetivos. Sem essas normas, a avaliação corre o risco de produzir juízos espontâneos e inconsistentes, sujeitos à labilidade dos pontos de vista destituídos de referência. Se isso ocorrer, a avaliação pode eventualmente potencializar mecanismos de controle e dominação, ao invés de cumprir seu papel pedagógico e formativo.

A perspectiva economicista e tecnocrática encarrega a educação da missão de ser a grande e talvez a principal portadora das possibilidades de êxito dos objetivos sociais do futuro. Ela pretende fazer pensar, assim, que "os objetivos educativos não são profundamente controvertidos, que a qualidade humana e a qualidade institucional podem ser abstraídas e medidas, que a educação se ocupa de coisas mensuráveis, que a atribuição de poder não supõe problema algum, que os sistemas sociais podem ser controlados mediante a ação administrativa e que o teórico do currículo é uma espécie de cientista" (REID apud CASANOVA, 1992, p. 18).

O proposto nesta investigação alicerça-se na importância de se avaliar e ter maiores informações sobre os egressos. Tais informações são pertinentes e necessárias para o entendimento real de sua trajetória acadêmica, ressaltando a qualidade do ensino, a busca do conhecimento, do saber, para educar, a contribuição social da pesquisa e a dinâmica do processo educacional. Maseto (2004) aponta para uma proposta de se realizar um processo de auto-avaliação dos programas de Pós-Graduação atendendo as informações solicitadas pela avaliação externa da CAPES e ao mesmo tempo, contribuindo para o seu desenvolvimento. A avaliação dos egressos da Pós-Graduação deve ser encarada, 
portanto, como parte integrante das ações dirigidas a tomadas de decisões, um processo estratégico e decisório que pode possibilitar a correção de rumos e a melhoria da realidade. Para Marrach (2000), a educação se insere no campo do social nossa avaliação leva em conta este contexto cuja liberdade econômica das grandes organizações não contém um conteúdo político democrático conforme o proposto na propalada democratização do ensino e do saber. A autora elenca os três objetivos propalados nesta retórica: um deles a respeito da qualificação do profissional para atender as demandas do mundo empresarial tanto em nível nacional quanto internacional, transformando a ciência e a técnica em capital técnico-científico. O segundo transforma a escola em um meio de transmissão dos princípios doutrinários da ideologia dominante. E por fim, a autora elenca a questão da escola funcionar de forma semelhante ao mercado em que o financiamento da educação acaba por aproveitar os subsídios estatais para consumir os produtos didáticos e para-didáticos do mercado escolar. Nas universidades (públicas e privadas) novos mecanismos de controle do tempo que o professor teria disponível para realizar pesquisas no campo educacional passam a ter propostas de diminuição de gastos e, portanto de achatamento salarial obrigando os docentes da desvalorizada área de humanas responder às demandas de mercado com pesquisas utilitárias ou oferta de cursos imediatistas. Assim, Marrach (2000) caracteriza este tipo de desqualificação da área de humanas resumida na palavra qualidade, ou seja, a excelência em pesquisa e o domínio de conhecimentos de alto nível têm que ser instrumentais e gerar tecnologias competitivas tendo em vista o mercado internacional. É a adequação da elite à sociedade tecnológica que exige mais gestores, mais administradores, mais técnicos com mentalidade empresarial.

\section{UNIVERSO DA PESQUISA E PROCEDIMENTOS METODOLÓGICOS}

A avaliação deste universo situa-se no campo das pesquisas educacionais de abordagem qualiquantitativa acerca dos egressos do Curso de Mestrado do programa de Pós-Graduação Stricto Sensu em Educação da UFU. Trata-se de um estudo de pesquisa populacional de egressos, definidos em comum acordo com a supervisora do programa de Pós-Graduação Stricto Sensu em Educação Escolar nível Mestrado da Universidade Federal de Uberlândia, Faculdade de Educação - Campus Santa Mônica na cidade de Uberlândia/MG, com informações obtidas junto à própria Instituição. Inicialmente entramos em contato com a Secretaria da Pós-Graduação da referida Instituição, solicitando junto à 
mesma uma listagem com dados de contato inerentes aos Egressos do Programa de Pós-Graduação Stricto Sensu Mestrado em Educação da UFU.

Conforme cronograma foi realizado o cadastramento dos egressos para envio de e-mail, contendo texto com instruções iniciais para colaboração no preenchimento do formulário apontado no link no próprio Termo de Consentimento Livre e Esclarecido para participação da mesma, atendendo à Resolução CNS 196/96. Por ocasião do envio dos e-mails, foi determinado o prazo de trinta dias para a sua devolução sendo este prazo prorrogado por mais vinte dias em razão do número da amostra ser inferior ao mínimo necessário. Em alguns casos, os egressos entraram em contato com o pesquisador via telefone e/ou via e-mail, a fim de esclarecer alguns aspectos do questionário e sanar dúvidas. Foram incluídos no estudo os egressos que concluíram o Mestrado até janeiro de 2004 até dezembro de 2009 do Programa de Pós-Graduação em questão. Foram excluídos os egressos cujos cursos foram interrompidos, incompletos e ainda aqueles recebidos após o prazo estipulado. Desta forma a amostra foi composta por sujeitos escolhidos, aleatoriamente e inseridos em categorias destacadas em alguns "quadros" que emergiram do empírico. Os dados foram coletados por meio do Questionário On-Line, com o intuito de contatar o maior número de egressos a fim de angariar maior número de informações possíveis dos mesmos e que satisfizessem os critérios de inclusão contemplando as seguintes questões, devidamente organizadas: identificação, dados familiares, formação acadêmica (ensino fundamental, médio e superior), estudos de PósGraduação, formação complementar, motivação, avaliação dos programas de Pós-Graduação, avaliação do corpo docente, pesquisa, produção científica, atividades profissionais e conclusão.

O referido instrumento foi avaliado por docentes de Instituições Públicas e Privadas, com o propósito de se verificar se ele se apresentava de forma clara e se atendia aos objetivos propostos pela pesquisa. Após as avaliações, foram realizadas as devidas alterações sugeridas pelos docentes, tornando-o mais acessível, abrangente, conciso e prático. Estes docentes apoiaram e aprovaram o instrumento em sua totalidade, salientando que o mesmo mostrava-se apto a mensurar o que se pretendia, enfatizando a clareza dos itens, a facilidade de leitura e interpretação, bem como a organização e a forma de apresentação.

Para facilitar o manuseio dos dados foi contratado um serviço de uma empresa de informática que desenvolveu o formulário vinculado ao banco de dados, que por sua vez facilitou toda a digitação. Este processo possui aspectos negativos se comparados com o formulário impresso, principalmente, pela falta de habilidades dos egressos nos meios informáticos e de comunicação via 
redes. Para os gráficos, cálculos e dados estatísticos foi utilizado o aplicativo Microsoft Excel. Por meio das funções destes aplicativos estabelecemos algumas frequências e fórmulas, demonstrando os resultados na forma de quadros e gráficos, o que favorece a análise e a interpretação.

Algumas dificuldades surgiram ao longo do tempo, particularmente, no que se refere à compatibilidade ou não dos endereços de contato dos egressos com a sua realidade atual. Muitos deles não tinham seus e-mails atualizados na Secretaria da Pós-Graduação ou não estavam com e-mail ativo e desta forma vinte e sete e-mails retornaram por estes motivos. Fato este, determinante da reação tecnologia e tempo de inserção na vida das pessoas. Cumpre salientar o fato de ter havido as mensagens de e-mail que chegaram ao destinatário correto, mas que, infelizmente, também não foram respondidas e devolvidas. Há de se considerar ainda as limitações e dificuldades existentes na obtenção de dados por meio de questionário eletrônico quando comparado a outros métodos de coleta. Os princípios éticos foram observados, os participantes cientes da importância do tema e da sua contribuição à população acadêmica de modo geral. Foram assegurados, aos mesmos o direito à privacidade e autonomia, pois foram enviados juntamente com o formulário, esclarecimento sobre o estudo, a importância da integridade nas respostas e o anonimato. Os formulários foram numerados em sequência lógica, garantindo o anonimato absoluto, seguindo as recomendações e normas de pesquisa, envolvendo seres humanos conforme Resolução 196/96 do Ministério da Saúde. O Termo de Consentimento permite análise e publicação dos dados. Os recursos financeiros para contratação do serviço de desenvolvimento do banco de dados on-line e outros custos adicionais que surgiram durante a execução do projeto foram de responsabilidade do pesquisador.

A seguir apresentamos o Perfil de Egressos do Curso de Mestrado em Educação da Universidade Federal de Uberlândia no que compreende o período do ano de 2004 à 2009.

\section{O PERFIL DOS EGRESSOS DO MESTRADO NA UFU}

São escassos na literatura na área consultada trabalhos no que tange à Avaliação de Egressos de Cursos de Pós-Graduação Stricto Sensu na Área de Educação, particularmente, naquela centrada na formação docente e de pesquisa nos ensinos superior, fundamental e médio. Para melhor compreensão passaremos a apresentar os resultados com gráficos e a discussão pertinente a seguir: 


\section{Gráfico 1 - Egressos Mestrado por Gênero}

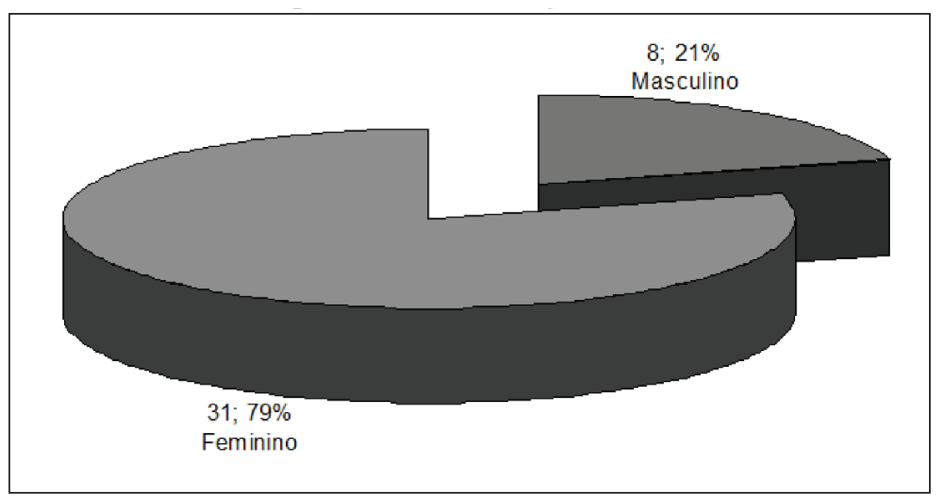

Como se pode notar nos Gráficos 1 e 2 dos trinta e nove (39) sujeitos investigados, trinta e um (79\%) do gênero feminino e apenas oito (21\%) do gênero masculino. Verifica-se aqui um predomínio do gênero feminino, assemelhandose aos dados obtidos por Gonçalves (2001) que vem de encontro a pesquisas do INEP (2007) que mostraram que as mulheres estão em maior número nas Instituições de Ensino, que alcançam maiores graus de escolaridade e melhores notas em testes de avaliação quando comparadas aos homens. Estes resultados também coincidem com site do IBGE (2007), que apresenta uma diferença muito grande em relação a formação por gênero na educação. Nota-se que, quando uma profissão, disciplina ou curso se feminiza passa a ocupar um lugar menos privilegiado que outras profissões. Este é o caso da educação que foi aceita como uma extensão do trabalho feminino. Isto se deve em parte à nossa sociedade que como se sabe é patriarcal, portanto, enquanto tendência histórica os homens ocupam as posições e profissões mais distintivas e privilegiadas social e economicamente.

No Brasil, dados do estudo trajetória da mulher na educação superior, do Instituto Nacional de Estudos e Pesquisas Educacionais - INEP (2007), que analisa a participação feminina destaca que a diferença entre os gêneros aumenta no decorrer da vida escolar partindo de apenas 1\% nas séries do Ensino Fundamental para cerca de 13\% na Graduação universitária. As idades encontradas nos sujeitos variam de vinte e cinco (25) a sessenta e um (61) anos, com média de quarenta e dois (42) anos, num total de sete solteiros, vinte e seis casados, seis divorciados e uma separada. 


\section{Gráfico 2 - Estado civil dos Egressos do Mestrado por Gênero}

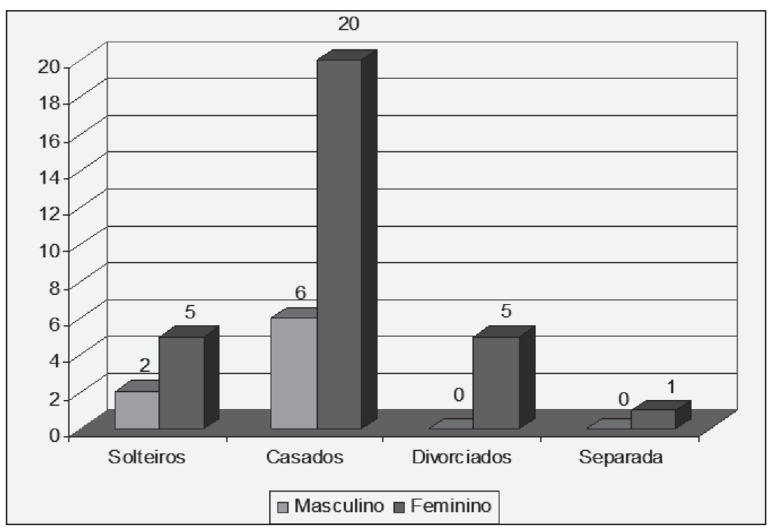

Quanto à sua origem a maioria deles vem de cidades do estado de Minas Gerais, o que provavelmente, se deve a localização mais próxima de Universidade em que o curso escolhido foi oferecido (Universidade Federal de Uberlândia - UFU). Daqueles que trabalham, vinte e cinco o fazem em Instituições Públicas, dezesseis em Instituições privadas e dois destes sujeitos são autônomos.

A análise dos dados da Graduação apresentados no Gráfico 3, mostra que $23 \%$ dos sujeitos obtiveram sua formação em Instituições particulares enquanto $77 \%$ em Instituições Públicas sendo que 3\% caracterizam sua formação em Filantrópica, 8\% Estadual e 66\% na Federal.

Gráfico 3 - Tipo de Instituição da Graduação dos Egressos

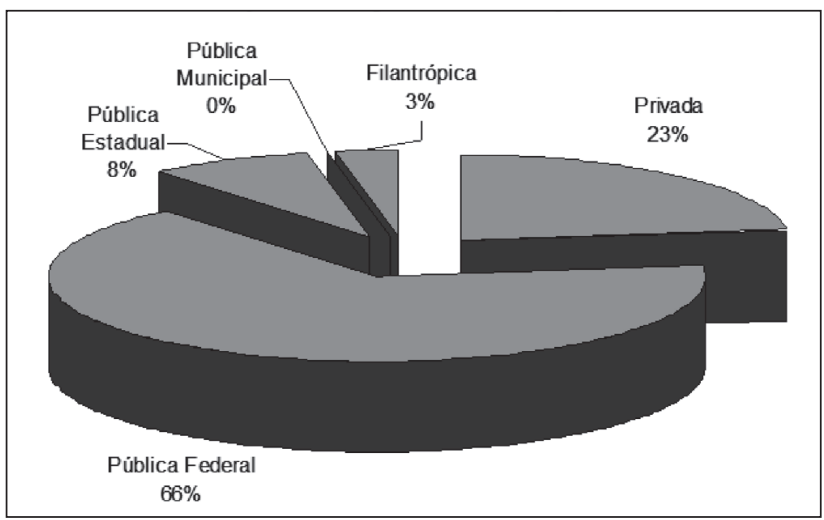


Estes achados identificam que os Egressos do Mestrado persistem nesta mesma Instituição pública para a sua formação acadêmica. Estes dados são, extremamente, reveladores uma vez que a escola pública na trajetória de estudo dos ensinos fundamental e médio desses depoentes concretamente cumpria a sua função em nossa sociedade, a saber: democratizava os códigos legítimos e socialmente valorizados em um determinado momento histórico, ou seja, a norma culta. Conhecimento este que tornou possível o ingresso e o êxito desses sujeitos na Pós-Graduação. Sendo que dos Egressos da pesquisa, trinta e um (31) fizeram algum tipo de Pós-Graduação, alguns com mais de duas pós-graduações e a maioria destes cursos estão ligados a educação que desta forma identifica o caminho pretendido.

Atualmente é sabido por todos que por conta das políticas de cunho neoliberal que se concretizam no sistema escolar oficial, principalmente nos ensinos fundamental e médio são desvalorizados o trabalho docente, suas condições de trabalho que efetivam finalmente no barateamento da qualidade de ensino. Diante desta realidade a escola já não é mais democrática, pois, a sua pretensa e competência em difundir o saber é impedida por esta realidade. No estudo de Gonçalves em 2001 constatou-se que grande parte da amostra pesquisada (69\%) era oriunda da escola pública. Isto mostra que desde a sua origem a escola pública tem participado da vida destes sujeitos. Além de contribuir na sua formação pode-se inferir que de certa forma, esta escola os incentivou a buscar mais, ao aprimoramento, a cursar uma Pós-Graduação, enfim, os estimulou à busca do saber docente. Nota-se que o ensino público mostrou-se para estes sujeitos, com qualidade suficiente para incentivá-los a nele permanecer até o nível superior.

No que se refere aos Cursos de Pós-Graduação nível Lato Sensu - Especialização, trinta e um (31) cursos foram cursados, vinte e cinco (25) egressos possuem algum tipo de cursos de pós-graduação, alguns com mais de três (3) pós-graduações e a maioria dos cursos estão ligados a área de educação.

No que se refere ao objeto de estudo do curso de Mestrado, a maioria gasta cerca de dois (2) anos para concluir o mestrado.

Destes sujeitos, doze (12) deles receberam bolsas oriundas de agências diversas, dados que diferem daqueles obtidos por Gonçalves em 2001 que relata que no Mestrado a grande maioria dos egressos fez o curso com bolsa de estudos. O ínfimo número e valor das bolsas oferecidas pelos órgãos de fomento em cursos de Pós-Graduação considerados de alto nível como este em estudo demonstra a pouca valorização do saber vinculado a uma área de conhecimento que acaba por ter deméritos em relação as outras áreas de conhecimentos como 


\section{Gráfico 4 - Tempo gasto no Mestrado}

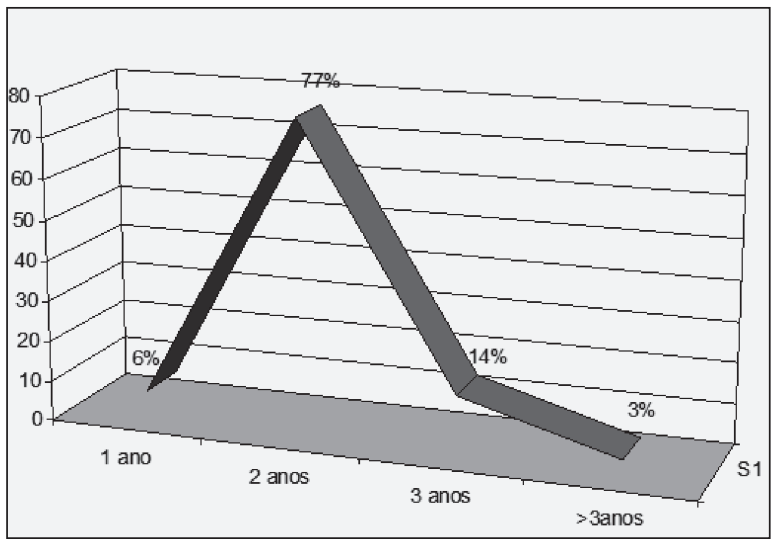

por exemplo, a biotecnologia, a engenharia genética, enfim, nas quais o sistema econômico vigente tem interesses em investir visando maior lucratividade. A própria distribuição de bolsas no interior das instituições comumente obedecem um critério de carência econômica, disponibilidade de tempo para o curso em nível de mestrado, deixando nos escalões inferiores a competência acadêmica ou o brilhantismo das pesquisas. Isto tende a ser, mais comum em áreas pouco valorizadas na hierarquia das ciências.

Verifica-se ainda que trinta e dois (32) tiveram algum tipo de incentivo para realizar o mestrado como redução de carga-horária de trabalho, liberação das suas atividades e afastamento remunerado. Chama a atenção o fato que sete (7) sujeitos não receberam bolsas, tendo cursado a Pós-Graduação às suas próprias expensas. Ora, causa estranheza o fato de que justamente o grupo do Mestrado que no início do seu aprimoramento e ampliação de conhecimentos, busca pelo saber, ser aquele que menos incentivo financeiro recebeu por parte dos órgãos competentes. Cumpre aqui questionar a(s) possível(is) repercussão(ões) que o precário incentivo financeiro de Mestrado pode acarretar como evasão ao longo do curso e redução no número de candidatos entre outros. Esta(s) repercussão(ões) podem ser menor(es) entre os doutores se considerarmos que os mesmos poderiam ter mais empregos e maior renda, ou seja, estarem financeiramente melhor estruturados. Não podemos aqui nos furtar a questionamentos de suma importância e que vem contrapor-se aos objetivos maiores da Pós-Graduação quais sejam, incentivar não só o ensino, mas também a pesquisa e a extensão. Como e o que fazer para estimular um pesquisador já na sua formação se ele deve ter rendimentos suficientes para manter-se no curso as 
suas próprias expensas, além, de se responsabilizar pelo seu próprio sustento? Onde está o apoio financeiro institucional e/ou governamental de fomento à pesquisa frente a esta realidade tão difícil e porque não dizer cruel? A nível de Instituição Pública, em que pese a maior flexibilidade em termos de carga horária, havendo maior disponibilidade de tempo para a pesquisa, como e o que fazer com o baixo nível salarial e suas repercussões negativas no desempenho docente e de pesquisador? E nas instituições particulares onde é muito maior a exigência em termos de carga horária em detrimento da pesquisa, que medidas e soluções seriam cabíveis e/ou exeqüíveis? E quanto à produção científica independentemente da Instituição ser pública ou privada, de publicações em termos qualiquantitativos tanto no país quanto no exterior, como e que recursos usar para incentivá-las?

Dos egressos, a busca constante do seu aprimoramento indica que apenas dois (2) concluíram o Doutorado, sendo que cinco (5) estão cursando e destes três (3) são bolsistas e os dois (2) não possuem nenhum tipo de incentivo. Dados estes que nos remetem aos questionamentos mencionados anteriormente.

As razões que levaram os sujeitos a ingressarem no Mestrado são elencadas no Gráfico 5 e que conforme se pode notar onze (11) indicaram a docência, dezoito (18) a profissão, com destaque aqui e que nos chama a atenção o fato de apenas dois (2) o interesse na pesquisa. Nota-se que os três aspectos mais relevantes são à busca da carreira docente, o aprimoramento profissional e o anseio de realizar pesquisa. Na análise destes aspectos há de se considerar que subjacente a eles, os sujeitos visam à melhoria em seus cargos, salários e novo status. Além disso, os docentes têm consciência acerca das lacunas na formação, o que os faz querer buscar novos saberes, aprofundar seus conhecimentos. Remontam-se à sua origem e trajetória educacional e desejam romper barreiras e aprimorar-se para mudar não só esta trajetória histórica, mas também as possibilidades de um viver melhor, mais consistente e porque não dizer mais digno. Em nosso estudo os dados evidenciam que o medo do desemprego estrutural ou os efeitos deste tipo de desemprego conduzem as pessoas de frações de classe menos abastadas às universidades, porque não encontram espaço para ascensão no mercado de trabalho. Passam a ser uma tentativa para não serem excluídos do mercado de trabalho no qual estão inseridos. Para tal, os sujeitos têm clareza da necessidade de obterem maior fundamentação que é oferecida pela escolaridade tanto em nível de Mestrado quanto de Doutorado, o que certamente converge numa maior e melhor visibilidade da sua carreira docente. Pode-se inferir a necessidade dos mesmos em 
manter e/ou buscar um vínculo empregatício satisfatório que contribua para a melhoria de seu próprio nível sociocultural. Nos dados do estudo de Gonçalves (2001) destacam-se como razões da busca do Mestrado o aperfeiçoamento da atividade profissional $(38,74 \%)$, a necessidade de ampliar os conhecimentos $(25,23 \%)$ e a qualificação para a docência $(23,42 \%)$, sendo o interesse pela pesquisa o motivo menos citado $(2,70 \%)$, dados este coincidente.

Gráfico 5 - Motivo da Titulação

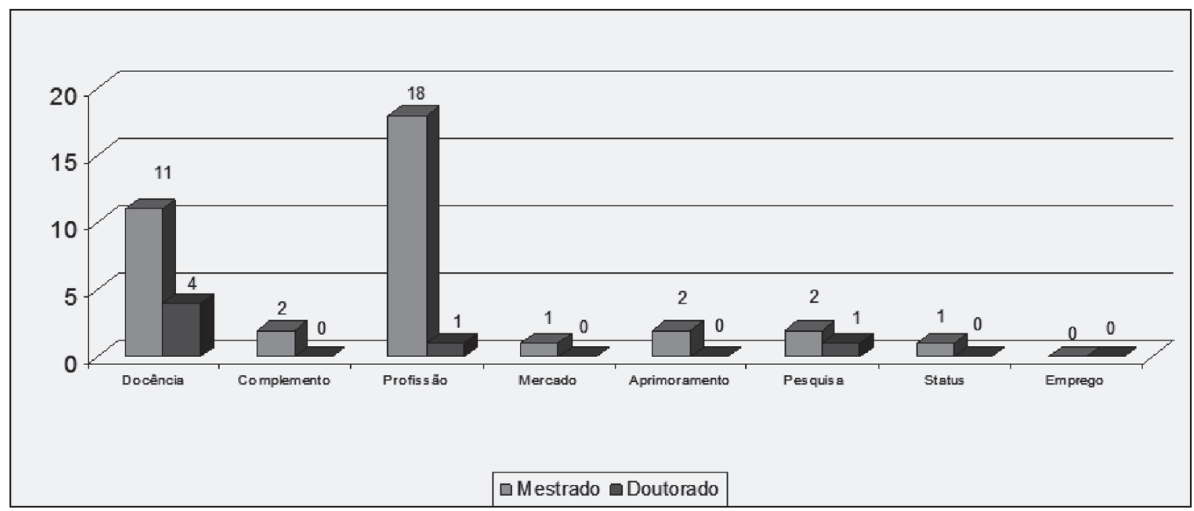

Devemos considerar que de alguma forma a sociedade tende a legitimar o que é aceitável e correto e os sujeitos acabam reproduzindo um discurso coerente com esses valores, conforme se pode observar nas suas afirmações, pois os dados mostram que os sujeitos construíram um discurso consentâneo com esta realidade. Melhor explicitando, os sujeitos, ao responderem aos questionamentos deste estudo suprimiram a necessidade concreta, real e material de suas condições e que este investimento acadêmico representa enquanto tendência, um passaporte distintivo para o exercício de funções melhor remuneradas e menos penosas, fato este, mascarado pelo discurso proferido destes sujeitos, mas, como já explicado, socialmente melhor aceito.

A busca pela carreira docente é também o aprimoramento de conhecimentos, é ser respeitado, é enfim, objetivar melhoria em cargos, salários e condições de vida de uma forma mais ampla o que nos remete a valores inerentes à sua origem familiar, pais e mães que não tiveram oportunidades e que por este motivo inserem seus filhos numa escola pública de qualidade e estes, nela percorrendo, buscam valorizar e desempenhar sua atividade profissional dentro de fundamentos concretos a fim de ter acesso ao conhecimento tendo em vista a valorização do saber, prerrogativa das classes dominantes (ESTEVAM, 2007). 
Aqueles que não detém o poder econômico, entendem que a ascensão social só lhes é possível a medida que investem no seu capital humano.

Vejamos a seguir os dados dos sujeitos quanto a avaliação de alguns dados relativos ao Mestrado:

Gráfico 6 - Avaliação itens Pós-Graduação

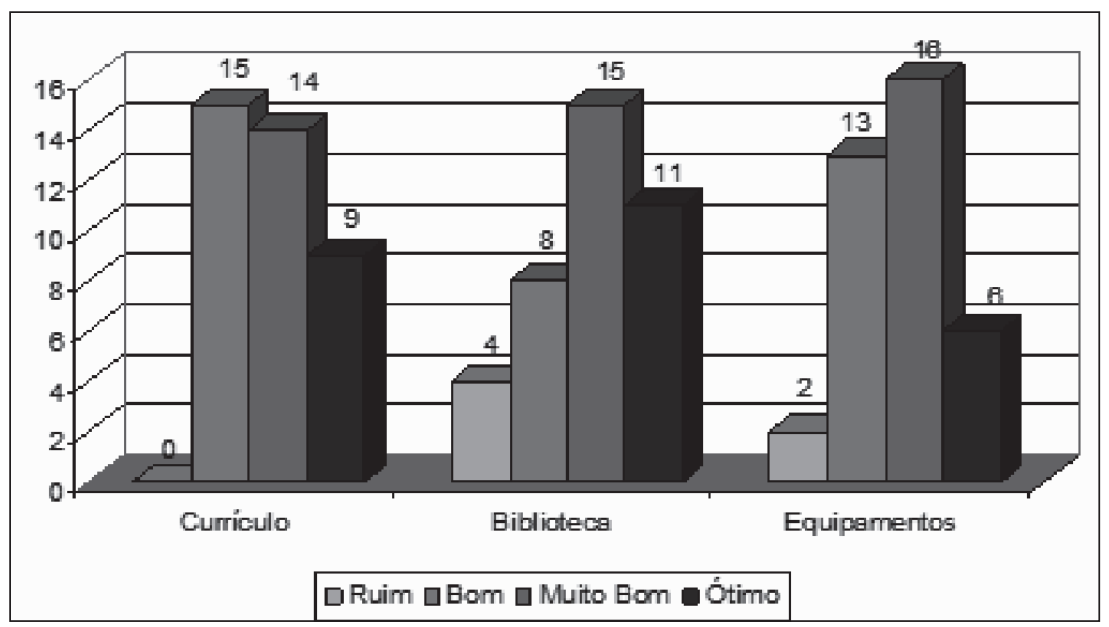

A avaliação de alguns itens da estrutura do programa de Pós-Graduação do Mestrado apresentada no Gráfico 6, mostra que a maioria dos sujeitos considera como "bom", "muito bom" e um número até significativo de "ótimo" o curso no que se refere ao currículo, biblioteca e equipamentos. Quanto ao corpo docente Gráfico 7, o resultado se repete no que tange à competência, dedicação, interesse e relacionamento. Esta avaliação evidencia a qualidade do curso oferecido ratificando a sua avaliação feita pela CAPES e alicerçada pelos escritos de Dias Sobrinho (2010) sobre as Universidades, que constituem um segmento que vem prestando uma valiosíssima contribuição à Educação Superior, à sociedade e ao Estado brasileiro.

Remontando à presença da escola pública na trajetória acadêmica dos sujeitos também fica evidenciado que a mesma teve um papel preponderante no prosseguimento dos estudos. Observa-se que a medida em que se aprofundam as desigualdades sociais e a lógica do livre mercado associada à competitividade faz com que estes sujeitos entendam como única alternativa de ascensão o prolongamento e/ou o prosseguimento dos estudos. Conforme Bueno (2000) trata-se da retomada do velho padrão funcionalista revisitando a teoria do 
Gráfico 7 - Avaliação itens Corpo Docente

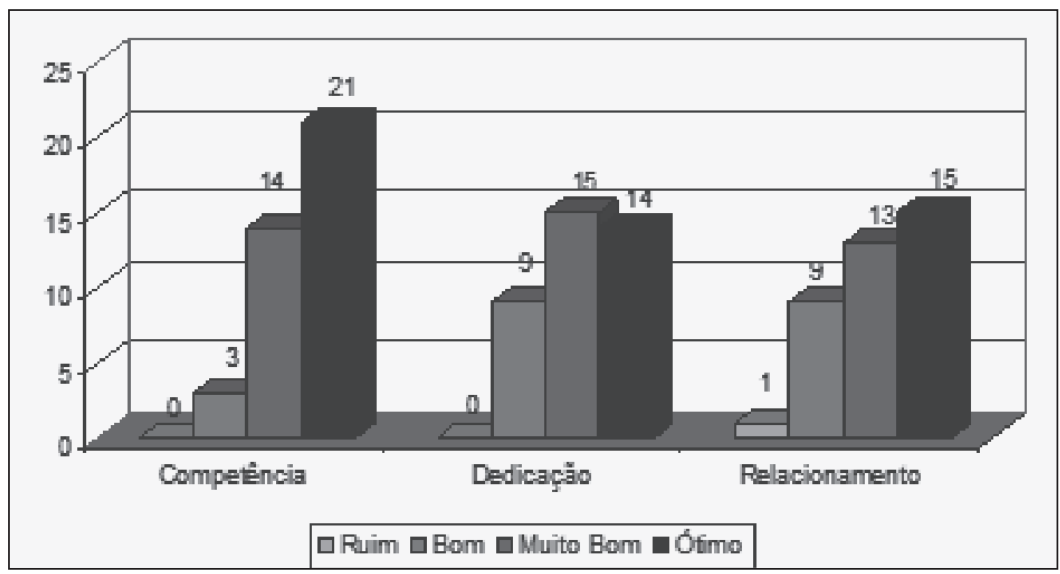

capital humano que supõe a mobilidade social como resultado do desempenho individual, reforçando o princípio da competição.

Quanto à pesquisa, os sujeitos puderam dimensioná-la no que se refere ao tipo de dedicação, o tempo de coleta de dados e à escolha do tema. Vejamos:

Gráfico 8 - Avaliação com relação à Pesquisa

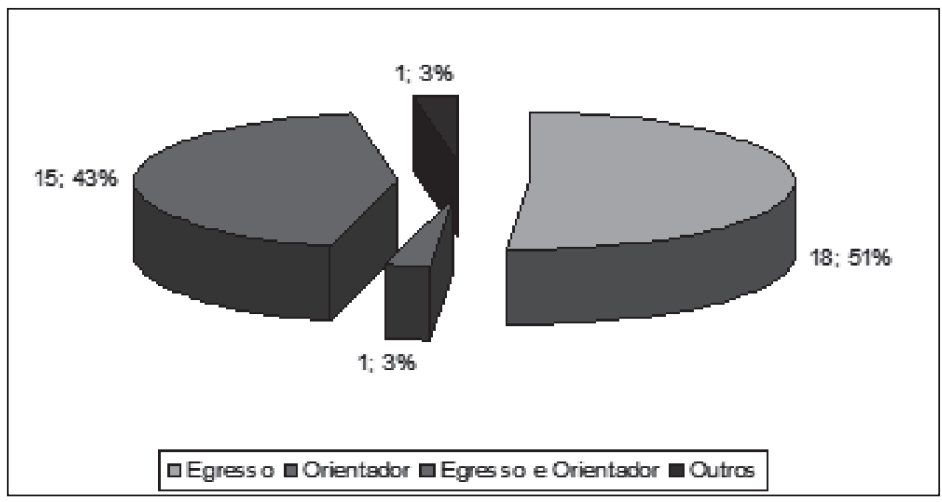

No Gráfico 8, verifica-se que a maioria dos sujeitos foi o responsável pela definição do tema da dissertação enquanto os demais o fizeram em comum acordo com o orientador. Isso chama a atenção para o fato de que não houve imposição e/ou influência na escolha dos temas e linhas de pesquisa. Este é um 
dado que demonstra que o programa de Pós-Graduação em questão propicia ao aluno certa autonomia. Este procedimento difere do que é observado em outras IES onde, numa postura no mínimo autoritária, é o orientador quem define ao aluno, qual e como será a sua pesquisa defendendo interesses mercadológicos de toda natureza. Essa minoria que chega a frequentar cursos de Pós-Graduação Stricto Sensu sobreviveu aos efeitos perversos do sistema escolar cujo processo de exclusão dos mais fracos só reforça o darwinismo social existente.

Gráfico 9 - Tempo gasto para a Pesquisa de Mestrado

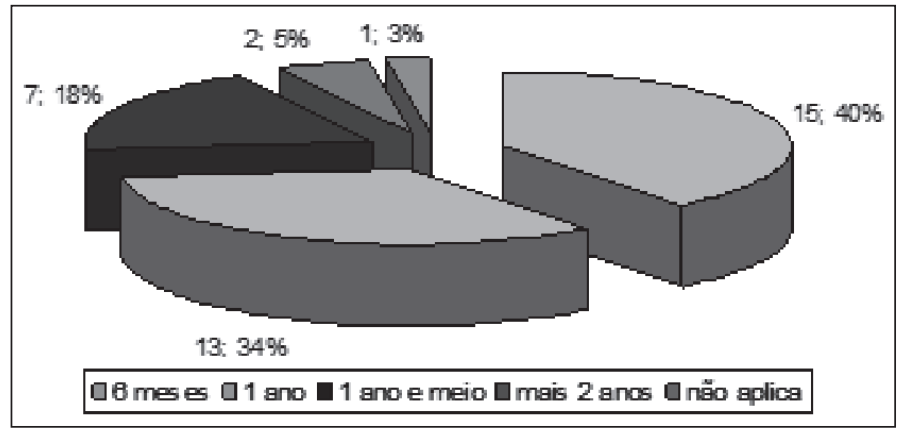

A análise do Gráfico 9, referente ao Mestrado mostra que a maioria dos sujeitos gastou cerca de seis meses a um ano para a coleta dos dados tendo sido consumidos então cerca de um ano e nove meses para o curso e integralização dos créditos.

Gráfico 10 - Dedicação ao Curso - Mestrado

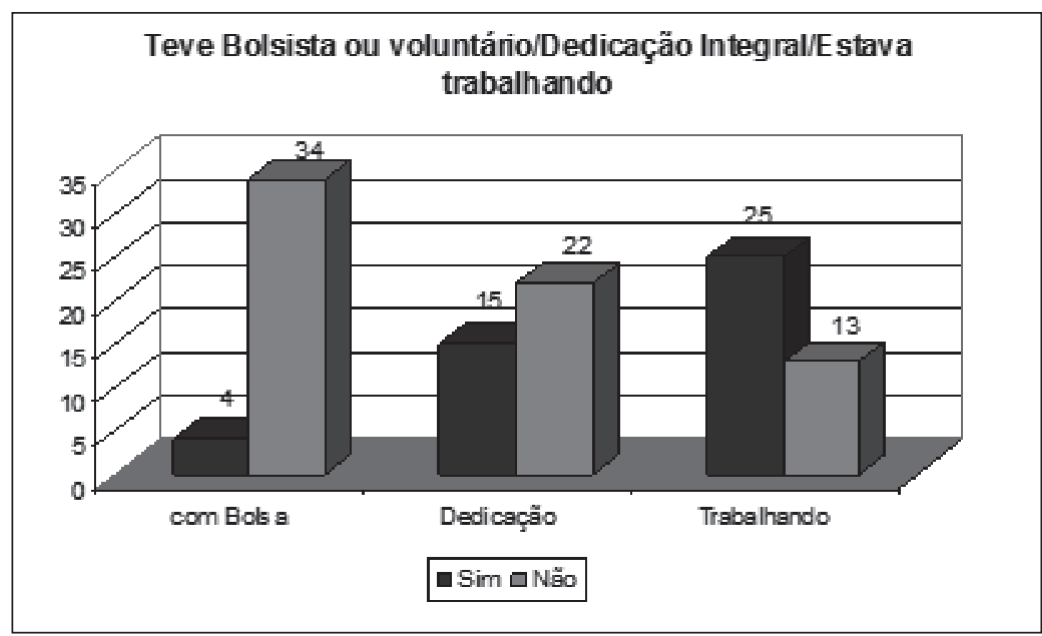


Verifica-se ainda que trinta e quatro (34-84\%) conforme Gráfico 10, não tiveram bolsista ou voluntário na coleta de dados, vinte e dois (22-59\%) não dedicaram integralmente para a pesquisa e vinte e cinco (25-66\%) estavam exercendo atividades na área da educação no tempo da sua pesquisa. Apesar do programa mostrar-se bom, plural, ter boa estrutura e bons docentes há que se considerar que o sujeito deve cursar disciplinas, integralizar créditos e proceder à qualificação e à defesa, o que, conforme análise dos dados, consumiu mais tempo que para a pesquisa em si. Há assim o risco de comprometimento da qualidade da pesquisa, o que é agravado pela não dedicação integral do aluno à mesma. Há aqui uma contradição qual seja, o sujeito vem buscar a pesquisa no curso de Pós-Graduação e durante o mesmo não dedica a ela tempo suficiente.

$\mathrm{Na}$ análise dos aspectos referidos é importante considerarmos conforme Demo (2005) que a questão não é apenas de tempo, mas de tempo de aprendizagem, já que aprender, como exige a própria natureza, toma muito tempo. Como conseguem realizar pesquisa, trabalhar, cursar disciplinas, integralizar créditos, não contando, além disso, com o precário apoio institucional de fomento à pesquisa conforme já discutido? Qual o reflexo disso no seu desempenho e na qualidade da sua produção? Não haverá repercussão no conceito e na avaliação periódica da Instituição?

A contradição inerente a estas questões elencadas é a relação que se estabelece entre o tempo e a produção científica, o que caracteriza o movimento no sentido do capital que entende produtividade como efeito imediatista do trabalho. Entendendo que o trabalho acadêmico, ou seja, o trabalho intelectual tem características diversas do trabalho produtivo, esta influência do mercado no ensino e na educação interfere sobremaneira em sua qualidade.

Quanto à produção científica verifica-se uma publicação maior que 414 dentre elas 365 nas publicações nacionais e 49 internacionais. Quais as razões para 19\% deles não terem publicação? Não seriam as mesmas questões discutidas relativas à necessidade de aliar trabalho, pesquisa e coleta de dados em curto espaço de tempo, além do não incentivo? Ou ainda, o baixo valor das bolsas que desestimulam os indivíduos a deixarem seus vínculos empregatícios e consequentemente sua remuneração responsável pela sua sobrevivência financeira para se dedicarem ao seu aperfeiçoamento docente e se dedicarem mais a pesquisa? Não seriam estes fatores cruciais de entrave na sua caminhada em direção àquilo que vem buscar? É um claro paradoxo de difícil compreensão, de um lado mestres e doutores que pouco pesquisam e não publicam e do outro a exigência Institucional e da própria CAPES na valorização da produção científica quando da pontuação dos cursos. Com as informações obtidas notamos 
que o sujeito vem demonstrando que no modelo em que está inserido ele não consegue publicar. Ele pode estar frustrado em sua busca. Será que ao ingressar no curso e na Instituição de sua preferência ele tinha consciência da trajetória real e dos entraves que iria enfrentar? Será que ele se dá conta de que ao final seus objetivos não foram amplamente atendidos?

Cabem aqui comentários de Gadotti (1991) quando afirma que predomina em muitos cursos de Pós-Graduação o "espírito da Graduação" onde os mestrandos vêm ao curso para "assistirem" aulas, completam os "créditos" e não conseguem depois escrever uma tese porque não se "exercitaram" durante os cursos (disciplinas). Além disso, eles precisam ter o direito de estudar, de ter uma vida acadêmica intensa por meio de participação em seminários e eventos a nível nacional e internacional. Quanto ao questionamento a cerca da publicação da Dissertação, 26\% dos sujeitos publicaram, 69\% não o fizeram e 5\% não responderam à questão. Estes que publicaram, o fizeram apesar da série de dificuldades levantadas anteriormente. Verifica-se ainda na mesma tabela que um número significativo de sujeitos (cerca de 38\%) atuam como orientadores, sendo setenta o número de alunos sob sua orientação e de cerca de duzentos e oitenta e cinco o de pesquisas já orientados pelos mesmos.

Observa-se que a maioria dos sujeitos atua como docentes em universidades públicas, que no que concerne à atividade atual a maioria deles está empregada no setor público. Estes dados estão de acordo com aqueles obtidos por Velloso (2004) que em seu estudo observou que quase $85 \%$ dos titulados de sua pesquisa trabalhavam em universidade e/ou instituições de pesquisa. Entre os egressos do estudo de Gonçalves (2001), a maioria também está na universidade onde atua tanto no ensino quanto na pesquisa. Interessante é, nos dados obtidos no presente estudo, a constatação de que a maioria dos sujeitos percorreu uma trajetória no serviço público e, concluindo seu aprimoramento em termo de formação docente e de pesquisador, a ele retornaram. Isso se deve as políticas universitárias contemporâneas de cunho neoliberal que são marcadas pela contenção de despesas e baixo investimento em educação, a concretização disso é a não abertura de novas vagas nas universidades e a contratação de estudantes de pós graduação para ministrarem aulas por tempo determinado e por um salário menor em comparação à aquele que seria despendido se fosse admitido um professor realmente habilitado e preparado para tal função. É interessante elucidar ainda que tal dado, ou seja, "constatação de que a maioria dos sujeitos percorreu uma trajetória no serviço público e, concluindo seu aprimoramento em termo de formação docente e de pesquisador, a ele retornaram," também foi revelado pelo estudo elaborado por Cusinato (1990) que ao analisar a efetiva 
participação da Unesp na formação dos Profissionais da Educação do ensino oficial público na cidade de Araraquara e região revelou, entre outras coisas, que esta Universidade tem uma grande participação na formação dos gestores escolares das instituições públicas de ensino: professores, supervisores de ensino, dirigente de ensino e técnicos pedagógicos, contrariamente ao que é veiculado pelo senso-comum, o estudo mostra, que o que realmente acontece é que os professores que estão em efetivo exercício em sala de aula e que tem um curso superior por uma universidade pública, se mostram mais ansiosos de prestar um concurso para ocupar outros cargos que o tirem dessa situação profissional. O estudo mostra claramente, ainda, o descontentamento do docente em sala de aula devido ao desprestígio social e moral atribuído a eles, que se concretizam de várias formas, desde a falta de respeito dos alunos até a violência corporal explícita por parte da comunidade estudantil. Nessa direção, o estudo mostra ainda, que a maioria dos gestores escolares que exercem cargos tais como: supervisão, coordenação e até a dirigente de ensino são possuidores de diplomas de ensino superior advindos majoritariamente de universidades públicas e muitos deles também são possuidores de títulos obtidos em cursos de pós- graduação realizados em centros de excelência. Dessa forma, concluímos que nesse momento histórico, possuir uma formação distintiva tende a ser um passaporte, um brevê que assegura a mudança deles para funções menos sofríveis vivenciadas por esses docentes em sala de aula.

Os resultados referentes a alguns questionamentos elencados mostram que a maioria dos sujeitos escolheria a mesma profissão, cursariam novamente o mestrado, optariam pela mesma área na Graduação e escolheriam o mesmo orientador. Quando questionados acerca do seu nível de satisfação com a profissão escolhida $76 \%$ deles mostraram-se satisfeitos. Estes resultados remontam ao seu grau de satisfação com o programa e orientação do curso concluído. Dados estes que se aproximam àqueles obtidos por Velloso (2004) ao analisar o nível de satisfação de mestres e doutores quanto à formação em pesquisa.

\section{CONCLUSÕES}

A busca de uma titulação em nível de Mestrado originou-se pela busca do saber que pudesse evidenciar que, o tipo de valorização que utilizam a educação como forma de dissolver os confrontos entre os interesses econômicos e sociais. Partiu-se do princípio que a educação é tratada nas políticas públicas como técnica e não como questão política social. Técnica que melhore a competência advinda da competição do mercado e as características mercadológicas 
das políticas públicas transpostas para o ideário educacional evidenciam a ingenuidade por vezes caracterizada nos dados.

Pudemos observar que: historicamente a educação no Brasil tem como característica o trabalho feminino, pois este é aceito como uma tarefa para mulheres. Nota-se que, quando uma profissão, disciplina ou curso se feminiza passa a ocupar um lugar menos privilegiado que outras profissões. Este é o caso da educação que tende a ser aceita como uma extensão do trabalho feminino. Isto se deve em parte à nossa sociedade que como se sabe é patriarcal, portanto, enquanto tendência histórica os homens ocupam as posições e profissões mais distintivas e privilegiadas social e economicamente. A maioria dos sujeitos freqüentou escolas públicas. Estes dados são extremamente reveladores uma vez que a escola pública na trajetória de estudo do Ensino Fundamental e Médio desses depoentes concretamente cumpria a sua função em nossa sociedade, a saber: democratizava os códigos legítimos e socialmente valorizados em um determinado momento histórico, ou seja, a norma culta. Conhecimento este que tornou possível o ingresso e o êxito desses sujeitos na Pós-Graduação. Atualmente é sabido por todos que por conta das políticas de cunho neoliberal que se concretizam no sistema escolar oficial, principalmente no Ensino Fundamental e Médio que desvalorizam o trabalho docente, suas condições de trabalho e se efetivam finalmente no barateamento da qualidade de ensino. Diante desta realidade a escola já não é mais democrática, pois, a sua pretensa proposta e competência para difundir o saber são impedidas por esta realidade. Nota-se que o ensino público mostrou-se para estes sujeitos, com qualidade suficiente para incentivá-los a nele permanecer, não somente na sua formação como também na sua carreira profissional militante. O medo do desemprego estrutural ou os efeitos deste tipo de desemprego conduzem as pessoas de frações de classe menos abastadas às universidades, porque não encontram espaço para ascensão no mercado de trabalho. Passam a ser uma tentativa para não serem excluídos do mercado de trabalho no qual estão inseridos. Para tal, os sujeitos têm clareza da necessidade de obterem maior fundamentação que é oferecida pela escolaridade tanto em nível de Mestrado quanto de Doutorado, o que certamente converge numa maior e melhor visibilidade da sua carreira docente. E a busca da carreira docente é também o aprimoramento de conhecimentos, é ser respeitado, é enfim, objetivar melhoria em cargos, salários e condições de vida de uma forma mais ampla o que nos remete a valores inerentes à sua origem familiar, pais e mães que não tiveram oportunidades e que por este motivo inserem seus filhos numa escola pública de qualidade e estes nela percorrendo buscam valorizar e desempenhar sua atividade profissional 
dentro de fundamentos concretos a fim de ter acesso ao conhecimento tendo em vista a valorização do saber, prerrogativa das classes dominantes. Aqueles que não detém o poder econômico entendem que a ascensão social só lhes é possível à medida que investem no seu capital humano. A avaliação da estrutura do programa de Pós-Graduação níveis de Mestrado e Doutorado mostra que a maioria dos sujeitos considera como "bom", "muito bom" e um número até significativo de "ótimo" o curso no que se refere ao currículo, biblioteca e equipamentos. Quanto ao corpo docente o resultado se repete no que tange à competência, dedicação, interesse e relacionamento. Esta avaliação evidencia a qualidade do curso oferecido, remontando à presença da escola pública na trajetória acadêmica dos sujeitos também fica evidenciado que a mesma teve um papel preponderante no prosseguimento dos estudos. Observa-se que à medida em que se aprofundam as desigualdades sociais, a lógica do livre mercado associada à competitividade faz com que estes sujeitos entendam como única alternativa de ascensão o prolongamento e/ou o prosseguimento dos estudos. Com relação à definição do tema da dissertação não houve imposição e/ou influência na escolha dos temas e linhas de pesquisa. Este é um dado que demonstra que o programa de Pós-Graduação em questão propicia ao aluno uma certa autonomia. Essa minoria que chega a freqüentar cursos de Pós-Graduação stricto sensu sobreviveu aos efeitos perversos do sistema escolar cujo processo de exclusão dos mais fracos só reforça o darwinismo social existente.

Apesar da avaliação do programa mostrar-se boa, plural, ter estrutura e bons docentes há que se considerar que o sujeito deve cursar disciplinas, integralizar créditos e proceder à qualificação e à defesa o que, conforme análise dos dados consumiu mais tempo que para a pesquisa em si. Há assim o risco de comprometimento da qualidade da pesquisa, o que é agravado pela não dedicação integral do aluno à mesma. Há aqui uma contradição qual seja, o sujeito que vem buscar a pesquisa no curso de Pós-Graduação e durante o mesmo não dedica a ela tempo suficiente, o que caracteriza o movimento no sentido do capital que entende produtividade como efeito imediatista do trabalho. Entendendo que o trabalho acadêmico, ou seja, o trabalho intelectual tem características diversas do trabalho produtivo, esta influência do mercado no ensino e na educação interfere sobremaneira em sua qualidade. Verifica-se ainda que um número significativo de sujeitos atua como orientadores de trabalhos, resultado este de mudanças na educação sobre os olhares da valorização da pesquisa. Observase que a maioria dos sujeitos atua como docentes em Instituições públicas. É a busca desenfreada por um status que lhes garanta sobrevivência e reconhecimento, ratificando este discurso no sentido de obter maior competência cursando 
uma Pós-Graduação. Interessante notar que a maioria dos sujeitos percorreu uma trajetória no serviço público e, concluindo seu aprimoramento em termos de formação docente e de pesquisador, a ele retornou para de alguma forma contribuir na transmissão do conhecimento adquirido e retribuir certa maneira o que lhes foi oferecido. Acabam, porém, ascendendo a cargos de coordenadores, supervisores e gestores, o que contraria a premissa de que queriam ser pesquisadores. A maioria dos sujeitos escolheria a mesma profissão, cursaria o Mestrado, optariam pela mesma área na Graduação e escolheria o mesmo orientador. Toda esta tendência de exclusão, marginalização e as exigências da "nova ordem mundial" fazem com que esta realidade simbólica caracterize a educação como algo a ser consumido e as contradições inerentes ao confronto de tensões entre os interesses econômicos e sociais refletem-se nas demandas dos sujeitos que buscam ascender socialmente a partir do valor da educação.

\section{REFERÊNCIAS}

BUENO, M. S. Infância, educação e neoliberalismo 2. ed. São Paulo: Cortez, 2000.

CAPES - Coordenação de Aperfeiçoamento de Pessoal de Nível Superior. Critério de avaliação. Disponível em: < http://www.capes.gov.br/avaliacao/ criterios>. Acesso em: 21 jul. 2007.

CASANOVA, M. A. La evaluación, garantía de calidad del Centro Educativo, Edelvives, Zaragoza, 1992.

CRONBACH, Lee J. Fundamentos de la exploracion psicologica, Madrid: Madrid, 1963.

CUSINATO, R. A formação do professor na área de estudos sociais. Araraquara/SP: UNESP, 1990.

DEMO, P. Ser professor é cuidar que o aluno aprenda. 4. ed. Porto Alegre: Mediação, 2005.

DIAS SOBRINHO, José. Universidade desconstruída: avaliação institucional e resistência. Florianópolis: Insular, 2000.

. Avaliação, Campinas, Sorocaba, v.15, n.1, 2010. Disponível em: $<$ http://www.scielo.br/scielo.php?script=sci_arttext\&pid=S1414$40772010000100001 \& \operatorname{lng}=$ pt\&nrm=iso\&tlng=pt $>$. Acesso em: 21 set. 2010. 
ESTEVAM, H. M. Avaliação do perfil de egressos do programa de pósgraduação stricto sensu em educação escolar: impacto na formação docente e de pesquisador. 2007. 107 f. Tese (Doutorado em Educação Escolar) - Faculdade de Ciências e Letras, Universidade Estadual Paulista "Júlio de Mesquita Filho", Araraquara, 2007.

GADOTTI, M. A Pós-Graduação em Educação. Campinas: Papirus, 1991. GLASS, G. V.; WORTHEN, B. R. Educational evaluation and research: similarities and differences. Curriculum Theory Network, Toronto, v. 3, p. 149-165, 1971.

GONÇALVES E. M. Discípulos do grupo comunicacional de São Bernardo do Campo: Avaliação de uma experiência acadêmica. Comunicação \& Sociedade, São Bernardo do Campo, v. 23, n. 36, p. 13-32, 2001.

IBGE. Revistas do Censo. Disponível em: < http://www.ibge.gov.br/ censo/>. Acesso em: 22 ago.2007.

INEP - Instinto Nacional de Ensino e Pesquisa. Trajetória da Mulher na Educação Brasileira, publicação do INEP/MEC e SPM, reúne diversos dados sobre as mulheres na educação do País de 1996 a 2003. Disponível em: $<$ http:// http://portal.inep.gov.br/c/journal/view_article_content?groupId =10157\&articleId=10983\&version=1.0>. Acesso em: 29 jul. 2007.

LAVILLE, Christian; DIONNE, Jean. A construção do saber. Manual de metodologia da pesquisa em ciências humanas. Adaptação da obra: Lana Mara Siman. Porto Alegre: Editora UFMG, 1999.

MARRACH, S. A. Neoliberalismo e Educação. In: SILVA JUNIOR, Celestino A. da et al. Infância, educação e neoliberalismo. 2. ed. São Paulo: Cortez, 2000

MASETO, Marcos. Autoavaliação em cursos de pós-graduação: teoria e prática. Campinas: Papirus, 2004.

SCRIVEN, M. The methodology of evaluation. In: TYLER, R. W.; GAGNÉ, R. M.; SCRIVEN, M. (Eds.). Perspectives of curriculum evaluation, Chicago, IL: Rand McNally, 1967. p. 39-83.

SILVA R.R.; BRANDÃO, D. Os quatro elementos da avaliação. Olho Mágico - Boletim da Rede Unida, São Paulo, v. 10, n. 2, p. 59-66, 2003. 
STAKE, R. The countenance of educational evaluation. Teachers College Recorá, New York, v. 68, n. 7, 1967.

STUFFLEBEAM, D. L. et al. Educational evaluation and decision making. Itasca, Illinois: F. E. Peacock Publishers, 1971.

TYLER, R. Accountability. Regional Oral History Office of the University of California. Berkeley, 1942.

VELLOSO, J. Mestres e doutores no país: destinos profissionais e políticas de Pós-Graduação. Cadernos de Pesquisa, São Paulo, v. 34, n. 123, 2004. VIANNA, M. R. A. O mestrado e o doutorado na faculdade de medicina da Universidade Federal de Minas Gerais - 1979 a 1995: uma avaliação pelo egresso, Belo Horizonte, 2000 Tese (Doutorado), Universidade Federal de Minas Gerais, Belo Horizonte, 2000. 